\title{
Echocardiographic assessment of maximum and minimum left atrial volumes: a population-based study of middle-aged and older subjects without apparent cardiovascular disease
}

\author{
Egil Henriksen · Jonas Selmeryd · Jerzy Leppert • \\ Pär Hedberg
}

Received: 2 June 2014/ Accepted: 5 September 2014/Published online: 12 September 2014

(c) The Author(s) 2014. This article is published with open access at Springerlink.com

\begin{abstract}
The aim of the present study was to obtain reference values of maximum and minimum left atrial volumes (maxLAV and minLAV, respectively) in a population-based subset without apparent cardiovascular disease or other factors potentially associated with left atrial enlargement. Because left ventricular diastolic dysfunction is commonly found in elderly subjects, we also tried to identify the presence of possible preclinical diastolic dysfunction in the study population. A population-based sample of 168 subjects (127 men and 41 women) underwent two-dimensional echocardiography using the singleplane disc method to determine maxLAV and minLAV. maxLAV and minLAV were indexed to body surface area (maxLAVi and minLAVi, respectively). maxLAVi was independent of age and sex, and produced reference limits (mean $\pm 1.96 \mathrm{SD}$ ) of $15-37 \mathrm{~mL} / \mathrm{m}^{2}$. minLAVi was correlated with age, and produced estimated reference limits of $3-15$ and $7-23 \mathrm{~mL} / \mathrm{m}^{2}$ in 40 - and 80 -year-old subjects, respectively. Based on the age-dependent reference values from the European Association of Cardiovascular Imaging, $<5 \%$ of the study population had possible preclinical left ventricular diastolic dysfunction. The present study established normal ranges for maxLAVi and minLAVi in a wellcharacterized population-based subset without apparent cardiovascular disease or other factors potentially associated with left atrial volume enlargement.
\end{abstract}

\footnotetext{
E. Henriksen · J. Selmeryd · P. Hedberg ( $₫)$

Department of Clinical Physiology, Västmanland County

Hospital, SE-72189 Västerås, Sweden

e-mail: par.o.hedberg@ltv.se

J. Leppert · P. Hedberg

Centre for Clinical Research, Västmanland County Hospital,

Uppsala University, Västerås, Sweden
}

Keywords Echocardiography · Left atrium · General population $\cdot$ Reference values

\section{Introduction}

For decades, the left ventricular ejection fraction has been used to predict cardiovascular outcomes. More recent data have shown that maximum left atrial volume (maxLAV) indexed for body surface area (maxLAVi) is an independent predictor of survival after myocardial infarction and congestive heart failure [1-5]. It has also been suggested that maxLAVi is less liable to fluctuate with short-term changes in loading conditions compared with Doppler filling indices and, therefore, maxLAVi has been proposed as a more specific marker of a persistent increase in left ventricular (LV) filling pressure [6]. The fact that maxL$\mathrm{AVi}$ carries independent prognostic information and seems to add indispensable information to the Doppler filling indices for assessing LV filling highlights the importance of measuring maxLAVi. Far less attention has been paid to the possibility that elevated filling pressure may cause a reduction in left atrial (LA) contractility, with a corresponding enlargement of minimum left atrial volume (minLAV). Consequently, minLAV indexed for body surface area (minLAVi) may have an additive value to the maxLAVi and Doppler filling indices in the evaluation of LV diastolic function [7].

In the guidelines of the American Society of Echocardiography/European Association of Cardiovascular Imaging (ASE/EACVI) [8], the given upper limit of maxLAVi is based on small cross-sectional studies performed in relatively young patient-based subsets during the 1980s $[9,10]$, in a small subgroup of 44 young patients [11], and in a group of 92 healthy volunteers [12]. In our 
clinical experience, the ASE/EACVI guidelines' recommended upper reference limit for maxLAVi is frequently encountered in adults without known or apparent cardiovascular disease. We set out to examine maxLAVi and minLAVi in a well-characterized population-based sample of people without apparent cardiovascular disease or other factors potentially associated with LA enlargement.

\section{Method}

\section{Study population}

The participants were recruited from the Västmanland Myocardial Infarction Study (VaMIS). Consecutive patients hospitalized for acute myocardial infarction from November 2005 to May 2011 were included in the VaMIS study. For each patient included, a control subject was recruited from the general population. A person with the nearest date of birth, same sex, and living in the same municipality as the VaMIS patient was identified in the Swedish Population register, in which all Swedish citizens are registered. All subjects underwent clinical examination, electrocardiography (ECG), echocardiographic examination, and blood sampling. From the control group of the VaMIS study $(n=855)$, we excluded individuals with a history of diabetes mellitus, hypertension, non-sinus rhythm, myocardial infarction, angina pectoris, transient ischemic attack/stroke, and symptoms of peripheral artery disease, as well as those taking regular cardiovascular or antihypertensive medication. In addition, subjects with a blood pressure $\geq 140 / 90 \mathrm{mmHg}$ measured at two separate occasions, a body mass index (BMI) $>35$, or categorized as New York Heart Association class II-IV were excluded from the study. Individuals with an abnormal echocardiographic wall motion score index, significant valvular disease, or missing values were also excluded. Finally, 168 individuals (127 men and 41 women) without apparent cardiovascular disease or comorbidity known to be associated with LV filling disorders were included in the analyses.

The study was approved by the Ethics Committee of Uppsala University, Sweden (Dnr 2005:382). All participants gave their written informed consent.

Image acquisition

A two-dimensional (2D) echocardiographic examination dedicated for research was performed using a commercially available Vingmed Vivid Seven (General Electric, Horten, Norway). All examinations were performed by an experienced echocardiographer (P.H.). The images were obtained in the left lateral recumbent position using a phased array transducer in the standard parasternal and apical views. The ECG-triggered 2D images and Doppler data were stored digitally in a cine loop format. Three consecutive cardiac cycles were recorded during quiet breathing.

\section{Echocardiographic analysis}

The analysis was performed by one of two experienced physicians (J.S. and P.H.) at least 3 months after the image acquisition and was performed using commercially available software (Echo PAC, PC version 110, Horten, Norway) with anonymized images. The LV cavity and wall dimensions were measured from the 2D images using the leading edge to leading edge principle. LV mass was estimated using the ASE-recommended formula [8].

In the assessment of LA volumes, the single-plane disk method was used in the apical 4-chamber view. The stored loops of this view were dedicated to LA visualization and oriented to maximize the LA area. maxLAV (i.e., end systolic) assessment was performed using the frame immediately preceding the mitral valve opening, and minLAV (i.e., end diastolic) was obtained using the frame contiguous to mitral valve closure. The LA endocardial border, excluding the LA appendage and the confluences of pulmonary veins, was traced with a straight line connecting the septal and lateral mitral leaflet base attachment points to the annulus as the superior border of the outlined area.

\section{Doppler filling indices}

Mitral inflow was recorded using pulsed Doppler at the tips of the mitral leaflets. The peak early (E) and late (A) transmitral diastolic flow velocities, the E/A ratio, and the deceleration time of the early filling velocity (MV-Edt) were obtained. The peak velocity of the early diastolic wave (TD-e') was measured using pulsed-wave tissue Doppler with the sample volume close to the mitral valve annulus in the apical 4-chamber view in the septal (TD-e' septal) and lateral (TD-e' lateral) walls. The E/e' ratio was calculated based on the transmitral $\mathrm{E}$ wave and the average of TD-e' lateral and TD-e' septal (TD-e' mean).

Because LV diastolic dysfunction is frequently observed in aged people and is associated with LA enlargement, we made an effort to evaluate the presence of possible preclinical diastolic dysfunction in the study population. Based on an algorithm and age-related reference values presented by the EACVI [13], possible diastolic dysfunction grade I was defined as the combination of TD- $\mathrm{e}^{\prime}$ mean $<9 \mathrm{~cm} / \mathrm{s}$, E/A ratio $<0.80$, and MV-Edt $>200 \mathrm{~ms}$ in subjects aged $\leq 60$ years. The corresponding cutoffs for 
subjects aged $>60$ years were TD-e $\mathrm{e}^{\prime}$ mean $<6 \mathrm{~cm} / \mathrm{s}$, E/A ratio $<0.60$, and MV-Edt $>200 \mathrm{~ms}$. Possible diastolic dysfunction grade II-III was defined as the combination of TD-e $\mathrm{e}^{\prime}$ mean $<9 \mathrm{~cm} / \mathrm{s}, \mathrm{E} / \mathrm{A}$ ratio $\geq 0.80$, and $\mathrm{E} / \mathrm{e}^{\prime}$ ratio $\geq 9$ in participants aged $\leq 60$ years. In subjects aged $>60$ years, the corresponding values were TD-e $\mathrm{e}^{\prime}$ mean $<6 \mathrm{~cm} / \mathrm{s}$, E/A ratio $\geq 0.60$, and $\mathrm{E} / \mathrm{e}^{\prime}$ ratio $\geq 9$.

Intra- and interobserver reproducibility of LA volume measurements

The reproducibility of LA volume measurement was determined by two sets of measurements in two separate readings in a sample of 19 randomly selected subjects. To determine the intraobserver reproducibility, the acquisitions were reanalyzed by the original observer at least 3 months after the first evaluation. The interobserver reproducibility was tested by a second reader using the same 19 participants.

\section{Statistical analysis}

Continuous data are expressed as the mean \pm standard deviation (SD) and categorical data are expressed as absolute values and percentages. The mean values for continuous variables were compared using the $t$ test. Adjusted means were estimated and compared by analysis of covariance. Categorical variables were compared using Fisher's exact test. Univariate relationships are expressed as Pearsońs correlation coefficients. Reference limits were estimated as the mean value $\pm 1.96 \mathrm{SD}$. In cases of age dependency (minLAVi), a parametric derivation of agerelated reference limits was performed according to Altman [14], and Royston and Wright [15]. A least-square regression analysis was used to model the mean of minL$\mathrm{AVi}$ as a function of age. Subsequently, the scaled absolute residuals (i.e., absolute residuals multiplied by the square root of $\pi / 2$ ) of the regression of minLAVi on age was used to model the function of SD on age. If the scaled absolute residuals showed no trend with age, the SD was estimated as the SD of the unscaled original residuals. Bivariate scatter plots with running-line smoothers were used to confirm the appropriateness of the linear models. Goodness of fit was evaluated via residual density plots, normal probability $(\mathrm{P}-\mathrm{P})$ plots, quantile $(\mathrm{Q}-\mathrm{Q})$ plots, and residuals-versus-fitted values plots. Centile curves were estimated using the formula: centile $=$ mean $+\mathrm{K} \times \mathrm{SD}$, where $\mathrm{K}$ is the corresponding centile of the standard Gaussian distribution (in our case, the 2.5th and 97.5th centile curves were estimated with $\mathrm{K}= \pm 1.96$ ). STATA version 12.1 (StataCorp LP, College Station, TX, USA) was used for all analyses. A $P$ value $<0.05$ was considered significant.
Table 1 Characteristics of the study population $(n=168)$

\begin{tabular}{lll}
\hline & $\begin{array}{l}\text { Men } \\
n=127\end{array}$ & $\begin{array}{l}\text { Women } \\
n=41\end{array}$ \\
\hline Age (years) & $59.9 \pm 9.7$ & $63.3 \pm 9.5$ \\
Current smoker & $14(11)$ & $5(12)$ \\
Height $(\mathrm{cm})$ & $179 \pm 6$ & $163 \pm 6$ \\
Weight $(\mathrm{kg})$ & $82 \pm 11$ & $66 \pm 11$ \\
Body mass index $\left(\mathrm{kg} / \mathrm{m}^{2}\right)$ & $25.5 \pm 2.7$ & $25.0 \pm 3.4$ \\
Body surface area (m $\left.{ }^{2}\right)$ & $2.02 \pm 0.15$ & $1.73 \pm 0.17$ \\
Systolic blood pressure (mmHg) & $132 \pm 8$ & $128 \pm 12$ \\
Diastolic blood pressure (mmHg) & $79 \pm 7$ & $76 \pm 7$ \\
NT-proBNP (ng/L) & $69 \pm 81$ & $102 \pm 61$ \\
Echocardiography & & \\
LV end diastolic diameter (mm) & $50.2 \pm 4.1$ & $46.5 \pm 3.9$ \\
Interventricular septum (mm) & $10.5 \pm 1.5$ & $9.5 \pm 1.4$ \\
LV posterior wall (mm) & $9.5 \pm 1.1$ & $8.7 \pm 1.2$ \\
LV mass (g) & $189 \pm 38$ & $148 \pm 31$ \\
MV-E (cm/s) & $53.9 \pm 11.6$ & $60.9 \pm 11.2$ \\
MV-A (cm/s) & $47.9 \pm 11.4$ & $54.5 \pm 11.7$ \\
E/A ratio & $1.19 \pm 0.41$ & $1.17 \pm 0.32$ \\
MV-Edt (ms) & $232 \pm 62$ & $211 \pm 46$ \\
TD-e' mean (cm/s) & $9.1 \pm 2.0$ & $8.9 \pm 2.2$ \\
E/e' ratio & $6.1 \pm 1.4$ & $7.1 \pm 1.8$ \\
Possible DD, grade I & $4(3)$ & $1(2)$ \\
Possible DD, grade II-III & $1(1)$ & $2(5)$ \\
\hline
\end{tabular}

$N T$-proBNP N-terminal pro-brain natriuretic peptide, $L V$ left ventricular, $M V$ - $E$ mitral valve E-wave, $M V$ - $A$ mitral valve A-wave, $M V$ $E d t$ mitral valve E-wave deceleration time, $T D-e^{\prime}$ mean peak early diastolic mitral annular velocity (average of septal and lateral walls), $D D$ diastolic dysfunction

The data are presented as the mean \pm standard deviation or number (percentages)

\section{Results}

Baseline characteristics

The baseline characteristics of the participants are presented in Table 1. The mean age \pm SD was $63.3 \pm 9.5$ (range 45-81) years and $59.9 \pm 9.7$ (range 38-81) years for women and men, respectively. The measured values of LV diastolic function were within the normal ageadjusted intervals in the vast majority of the participants. An E/ $/ \mathrm{e}^{\prime}$ ratio of $\geq 9$ was found in $5.4 \%$ of the study population, and no individual had an $\mathrm{E} / \mathrm{e}^{\prime}$ ratio $>14$. Possible preclinical diastolic dysfunction was present in eight $(4.8 \%)$ of the participants, three of whom had an $\mathrm{E} / \mathrm{e}^{\prime}$ ratio of $\geq 9$. An $\mathrm{N}$-terminal pro-brain natriuretic peptide (NT-proBNP) level $>200 \mathrm{ng} / \mathrm{L}$ was found in $7 \%$ of the subjects. Two participants had an NT-proBNP level $>300 \mathrm{ng} / \mathrm{L}$ (546 and $548 \mathrm{ng} / \mathrm{L}$, respectively). They were both men, aged 59 and 69 years, with E/A ratios of 
Table 2 Maximum and minimum left atrial volumes according to $\operatorname{sex}$

\begin{tabular}{lllc}
\hline LA volumes & $\begin{array}{l}\text { Men } \\
n=127 \\
\text { Mean } \pm \mathrm{SD}\end{array}$ & $\begin{array}{l}\text { Women } \\
\text { Mean } \pm \mathrm{SD}\end{array}$ & $P$ value $^{\mathrm{a}}$ \\
\hline maxLAV $(\mathrm{mL})$ & $51.7 \pm 11.9$ & $43.8 \pm 10.6$ & $<0.001$ \\
$\operatorname{minLAV~}(\mathrm{mL})$ & $21.4 \pm 7.5$ & $20.9 \pm 7.5$ & 0.71 \\
Indexed to BSA & & & \\
$\operatorname{maxLAVi}\left(\mathrm{mL} / \mathrm{m}^{2}\right)$ & $25.6 \pm 5.9$ & $25.2 \pm 5.3$ & 0.69 \\
$\operatorname{minLAVi}\left(\mathrm{mL} / \mathrm{m}^{2}\right)$ & $10.7 \pm 3.9$ & $12.0 \pm 3.9$ & 0.056 \\
\hline
\end{tabular}

$\max L A V$ maximum left atrial volume, $\min L A V$ minimum left atrial volume, $B S A$ body surface area

${ }^{\text {a }}$ For differences between men and women $(t$ test)

Table 3 Univariate correlations between demographic and anthropometric measures and maximum and minimum left atrial volumes indexed for body surface area

\begin{tabular}{|c|c|c|c|c|}
\hline & \multicolumn{2}{|c|}{$\max L A V i$} & \multicolumn{2}{|c|}{$\min L A V i$} \\
\hline & $r$ & $P$ value & $r$ & $P$ value \\
\hline Sex & 0.03 & 0.69 & -0.15 & 0.056 \\
\hline Age & 0.11 & 0.17 & 0.39 & $<0.001$ \\
\hline Height & -0.01 & 0.87 & -0.20 & 0.011 \\
\hline Weight & -0.05 & 0.56 & -0.19 & 0.016 \\
\hline BMI & -0.05 & 0.54 & -0.07 & 0.37 \\
\hline
\end{tabular}

max $L A V i$, maximum left atrial volume indexed for body surface area; minLAVi, minimum left atrial volume indexed for body surface area; $B M I$, body mass index

0.91 and 1.34 , respectively, and $\mathrm{E} / \mathrm{e}^{\prime}$ ratios of 4.2 and 5.3 , respectively.

\section{LA volumes}

The LA volumes in men and women are presented in Table 2. maxLAV was significantly greater in men compared with women; however this sex difference disappeared after indexing maxLAV to body surface area. Although minLAV did not differ between women and men, after indexing to body surface area, there was a trend toward a higher minLAVi in women compared with men (12.0 vs $\left.10.7 \mathrm{~mL} / \mathrm{m}^{2} ; P=0.056\right)$. However, after adjusting for age, this sex difference in minLAVi was attenuated (estimated mean, $11.6 \mathrm{vs} 10.8 \mathrm{~mL} / \mathrm{m}^{2}$ for women and men, respectively; $F=1.54, P=0.22$ ).

Table 3 shows the univariate analysis of the relationships between demographic and anthropometric measures and maxLAVi and minLAVi. There were no significant relationships between maxLAVi and age, sex, or measures of body size. In contrast, minLAVi was significantly correlated with age (although the correlation coefficient was low) and borderline significantly correlated with sex. Even

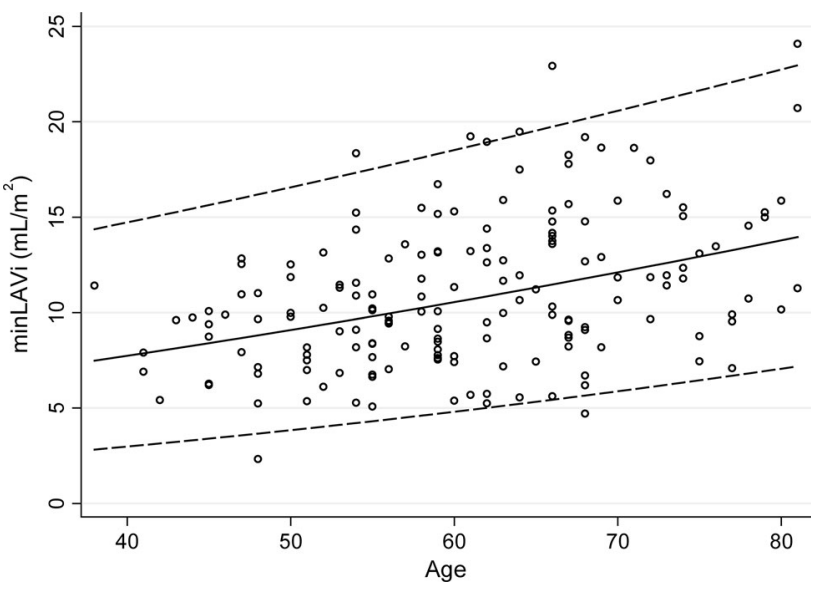

Fig. 1 Minimum left atrial volume indexed for body surface area (minLAVi) according to age, and reference curves for estimated mean (solid line) and $-1.96 \mathrm{SD}$ and $+1.96 \mathrm{SD}$ (dashed lines)

Table 4 Reference intervals for maximum and minimum left atrial volumes indexed for body surface area

\begin{tabular}{ll}
\hline & Reference interval \\
\hline $\operatorname{maxLAVi}\left(\mathrm{mL} / \mathrm{m}^{2}\right)$ & $15-37$ \\
$\operatorname{minLAVi}\left(\mathrm{mL} / \mathrm{m}^{2}\right)$ & \\
At 40 years of age & $3-15$ \\
At 60 years of age & $5-18$ \\
At 80 years of age & $7-23$ \\
\hline
\end{tabular}

maxLAVi, maximum left atrial volume indexed for body surface area; $\min L A V i$, minimum left atrial volume indexed for body surface area

${ }^{a}$ Reference interval for maxLAVi was estimated as the mean \pm 1.96 $\mathrm{SD}$. Reference intervals for minLAVi were calculated according to the regression equation: $(1.85+0.023 \times \text { age } \pm 1.96 \times 0.54)^{2}$

after indexing for body surface area, minLAVi remained significantly associated with height and weight. However, in multivariable linear regression models that included age, sex, and height, weight, or BMI entered separately, only age remained a significant independent predictor of minLAVi $(P<0.001$ in all models $)$.

The reference interval for maxLAVi was estimated as $15-37 \mathrm{~mL} / \mathrm{m}^{2}$ (mean $\pm 1.96 \mathrm{SD}$ ). As expected, $2.4 \%$ $(n=4)$ of the participants had a maxLAVi $>37 \mathrm{~mL} / \mathrm{m}^{2}$.

Because of the significant relationship between minL$\mathrm{AVi}$ and age, we estimated the reference interval via general linear regression using minLAVi as the dependent variable and age as the predictor. A slight departure from a Gaussian distribution and some heteroskedasticity of the residuals were effectively corrected by an initial square root transformation of minLAVi. The final back-transformed model of estimation of the reference interval for minLAVi was $(1.85+0.023 \times \text { age })^{2} \pm(1.96 \times 0.54)^{2}$ and is displayed graphically in Fig. 1 . The reference 
intervals for maxLAVi and minLAVi are presented in Table 4.

Reproducibility of LA volume measurements

The intra- and interobserver reproducibility, expressed as the absolute mean difference $\pm \mathrm{SD}$, and the coefficient of variation $(\mathrm{CV})$ for the maxLAV measurements were $2.6 \pm 4.1 \mathrm{~mL} \quad(\mathrm{CV} \quad 8.0 \%)$ and $1.2 \pm 6.1 \mathrm{~mL} \quad(\mathrm{CV}$ $11.9 \%)$, respectively. The corresponding figures for the intra- and interobserver reproducibility of the minLAV measurements were $1.3 \pm 3.8 \mathrm{~mL}(\mathrm{CV} 16.1 \%)$ and $1.6 \pm 4.5 \mathrm{~mL}(\mathrm{CV} 19.2 \%)$, respectively.

\section{Discussion}

In the present population-based study, the distributions of maximum and minimum LA volumes were studied in 168 randomly selected subjects without apparent cardiovascular disease or comorbidity known to be related to LA enlargement. The current data confirm that maxLAVi was independent of age and sex, and displayed an upper normal limit of $37 \mathrm{~mL} / \mathrm{m}^{2}$. In contrast, minLAVi was correlated with age, and exhibited estimated upper reference limits of $15 \mathrm{~mL} / \mathrm{m}^{2}$ and $23 \mathrm{~mL} / \mathrm{m}^{2}$ in subjects aged 40 and 80 years, respectively.

LA enlargement has been proposed as a barometer of diastolic burden and as a predictor of stroke, heart failure, and cardiovascular death. Therefore, it is important to include maxLAVi in the standard echocardiographic examination $[1-6,16]$. However, this apparently simple assignment presents several problems. Several imaging techniques, such as echocardiography, cardiomagnetic resonance imaging, and high-resolution computed tomography, have been used to obtain LA volumes [10, 17-21]. The geometric models and methods used for LA measurement vary between single or biplane methods, 3D models, area-length models, and disc models. The differences in LA volume measurements between different studies and methods are disturbingly large and emphasize the need for proper population-based reference values for the actual method used.

In the present study, the upper limit of the reference interval for maxLAVi was $37 \mathrm{~mL} / \mathrm{m}^{2}$, as measured using the apical 4-chamber single-plane disk method. In comparison, the mean $+2 \mathrm{SD}$ of biplane Simpson indexed LA volumes reported in the 1980 s by two smaller studies $(n<60)$ of young healthy volunteers (mean age $<40$ years) were slightly lower, at 34 and $32 \mathrm{~mL} / \mathrm{m}^{2}$, respectively $[9,10]$. In a healthy subgroup $(\mathrm{n}=44)$ with a mean age of 39 years and free from possible diastolic dysfunction, Tsang et al. [11] reported an upper reference limit (mean $+2 \mathrm{SD}$ ) of $32 \mathrm{~mL} / \mathrm{m}^{2}$. In a patient population free from apparent cardiovascular disease, Thomas et al. [12] observed upper reference limits of 39 and $35 \mathrm{~mL} / \mathrm{m}^{2}$ in the subgroups younger $(n=47)$ and older $(n=45)$ than 50 years, respectively. Identical to our finding, Kou et al. [22] reported an upper reference limit of $37 \mathrm{~mL} / \mathrm{m}^{2}$ in a very recent large multicenter study of healthy volunteers $(n=734)$. Interestingly, their estimated upper reference limit of maxLAVi from the single-plane 4-chamber view was exactly the same (i.e., $37 \mathrm{~mL} / \mathrm{m}^{2}$ ) as their biplane estimate.

In the ASE/EACVI guidelines, the upper limit of maxLAVi is reported as $\leq 28 \mathrm{~mL} / \mathrm{m}^{2}$ [8]. Obviously, the recommendation is not only derived from cross-sectional studies of healthy subjects, but is also based on the estimated risk related to LA volume and on expert opinion. According to previous cross-sectional studies, the guideline-recommended reference limit of $28 \mathrm{~mL} / \mathrm{m}^{2}$ would approximately correspond to a population mean +1 SD in an apparently healthy population. The use of $1 \mathrm{SD}$ to define normality is notable, as it surely will categorize otherwise-healthy individuals as diseased. Certainly, LA volumes $\geq 28 \mathrm{~mL} / \mathrm{m}^{2}$ have been reported to be predictive of future congestive heart failure [4] and compound cardiovascular events [23]. An even lower LA volume of $\geq 27 \mathrm{~mL} / \mathrm{m}^{2}$ has been reported as being predictive of future atrial fibrillation in patients with hypertrophic cardiomyopathy [24]. Most biological risk markers measured on a continuous scale are likely to display a risk continuum without an exact point above which the risk suddenly increases, and an increased risk can even be detected at levels that are considered to be within the distribution of the healthy population (e.g., serum cholesterol [25] and blood pressure [26] ). In fact, the concept of "optimal" prognostic thresholds has recently been questioned [27]. Risk stratification is not straightforward, as it requires multifactorial considerations in a clinical context and cannot be simplified axiomatically into a threshold of a single parameter. In our opinion, the reference limits should be thresholds dedicated to inform the clinician about the distribution of a marker in the healthy population, separate from prognostic or therapeutic decision limits.

As expected, the maxLAV was larger in men than in women in the present study. However, this sex difference disappeared after adjusting for body surface area. Some studies have not found a relationship between maxLAVi and age $[10,12,19]$, whereas others have done so [28]. The present data showed no significant correlation between age and maxLAVi.

In the early nineties, Appleton et al. [7] noticed that a minLAV of $\geq 40 \mathrm{~mL}$ predicted a pulmonary wedge pressure $>12 \mathrm{mmHg}$ with a sensitivity and specificity of 82 and $98 \%$, respectively. Until recently, minLAV was almost ignored. The left atrial function has traditionally been 
described as modulating LV filling in three phases: the reservoir phase (during atrial relaxation and LV systole, ending up in maxLAV), and the conduit and the atrial contraction phases (during LV filling, ending up in minLAV). As opposed to that observed during the reservoir phase, during the conduit and atrial contraction phases, the LA is directly exposed to LV pressure. An increase in LV filling pressure may directly affect LA pressure and, therefore, LA size. Consequently, minLAV may be a more sensitive marker of an increased LV filling pressure than maxLAV. Supportive of this hypothesis, Russo et al. [29] recently found a considerably stronger association between $\mathrm{E} / \mathrm{e}^{\prime}$ ratio and minLAV than between $\mathrm{E} / \mathrm{e}^{\prime}$ ratio and maxLAV.

The present study confirmed previous findings that minLAVi increase with age $[28,30]$; however, we did not assess the pre-atrial contraction volume and may, therefore, only speculate on this age dependency. In contrast with the LA reservoir function, previous studies have shown that the conduit function deteriorates with age [28, 30]. The observed decrease in passive atrial emptying is most likely related to changed LV filling properties associated with age. However, the LA contraction function seems to be maintained or even amplified with age [28, 30]. The observed increase in LA active pump function with age may be a compensation for the impaired early filling and is possibly mediated by the Frank-Starling mechanism. However, the fact that our data and those of others showed a rise in minLAVi with age suggests that increased atrial contractility may not fully compensate for the age related decrease in passive LA emptying.

The intra- and interobserver reproducibility of the LA volume measurements in the present study were very similar to the recent findings of Aune et al. [19], including a slightly poorer reproducibility for minLAV compared with maxLAV. As the LA is at its smallest size at minLAV, the echo broadening in atrial septum increases because of an augmentation in atrial septal thickness, rendering it harder to identify the true wall echoes, which may explain the difference in reproducibility observed between minLAV and maxLAV.

Because LA enlargement is observed frequently in subjects with LV diastolic dysfunction, a condition that presents frequently in elderly individuals, we made an effort to exclude the possibility of a systematic bias, i.e., that several of the participants had preclinical diastolic dysfunction. Therefore, conventional Doppler indices, tissue Doppler filling indices, and NT-proBNP levels were analyzed. The distributions of diastolic Doppler measurements in the present study population were within what could be expected in a population without apparent cardiovascular disease compared with findings from a large Scandinavian study of healthy subjects [31]. In addition, based on an
EACVI-guideline-recommended algorithm [13], an analysis suggested a low burden of possible preclinical diastolic dysfunction in the present study population.

\section{Limitations and strengths}

The present population-based subset of men and women were all of northern European descent; therefore, the extent to which the data can be extrapolated to other ethnic groups is not known. Only 41 (24\%) of the participants were women, which may have reduced the statistical power. The main reason for the sex difference was that, for each patient included in the VaMIS study, a control subject matched for age and sex was recruited from the general population. Consequently, the sex distribution of the control subjects who were enrolled in the present study reflects the sex difference in patients hospitalized for myocardial infarction.

Unfortunately, the acquisition and storage of loops dedicated to LA planimetry were only obtained in the 4-chamber view, and not in the 2-chamber view in the present study. Thus, the guideline-recommended biplane assessment of LA volumes [8] was not possible, which represented a limitation of the study. However, biplane planimetry is quite often unfeasible because of suboptimal image quality in the apical 2-chamber view, preventing adequate visualization of the LA anterior wall [21]. Lester et al. [32] demonstrated that the mean \pm SD of the absolute difference between the single-plane and biplane disc methods was $6 \pm 5 \mathrm{~mL}$, indicating a strong agreement between the two methods. Although bi- and single-plane assessment of LA volumes are not interchangeable, previous studies have suggested that the single-plane method may be acceptable for clinical use if reference limits that are specific for the method are available [21, 32].

The intra- and interobserver variability was obtained from the same set of images, i.e., only the measurement variability was tested, and not inconsistencies caused by variations in imaging planes or beat-to-beat variations.

The strengths of the present study included the population-based design and the well-characterized participants without signs of cardiovascular disease or risk factors and who were not taking any medications. The evaluation of LV diastolic function and NT-proBNP concentration was important considering the well-known association between LV filling function and LA volumes [13].

\section{Conclusions}

In the present population-based random sample of middleaged and older subjects without known or apparent 
cardiovascular disease or comorbidity, the maximum and minimum LA volumes were studied using the single-plane disc method. The current data confirmed that maxLAVi is independent of age and sex, and showed that it displayed an upper normal limit of $37 \mathrm{~mL} / \mathrm{m}^{2}$. In contrast, minLAVi was correlated with age and exhibited estimated upper reference limits of 15 and $23 \mathrm{~mL} / \mathrm{m}^{2}$ in subjects aged 40 and 80 years, respectively.

Acknowledgments We thank Petra Wahlén, Lena Trollvad, Lolita Backsell, Marja-Leena Ojutkangas, Annika Kärnsund, and Göran Nilsson for valuable contributions. This study was supported by grants from Sparbanksstiftelsen Nya, the County of Västmanland, Selanders Stiftelse, and the Swedish Medical Association.

\section{Conflict of interest None.}

Open Access This article is distributed under the terms of the Creative Commons Attribution License which permits any use, distribution, and reproduction in any medium, provided the original author(s) and the source are credited.

\section{References}

1. Rossi A, Cicoira M, Zanolla L, Sandrini R, Golia G, Zardini P, Enriquez-Sarano M (2002) Determinants and prognostic value of left atrial volume in patients with dilated cardiomyopathy. J Am Coll Cardiol 40:1425-1430

2. Møller JE, Hillis GS, Oh JK, Seward JB, Reeder GS, Wright RS, Park SW, Bailey KR, Pellikka PA (2003) Left atrial volume: a powerful predictor of survival after acute myocardial infarction. Circulation 107:2207-2212. doi:10.1161/01.cir.0000066318. 21784.43

3. Sabharwal N, Cemin R, Rajan K, Hickman M, Lahiri A, Senior R (2004) Usefulness of left atrial volume as a predictor of mortality in patients with ischemic cardiomyopathy. Am $\mathrm{J}$ Cardiol 94:760-763. doi:10.1016/j.amjcard.2004.05.060

4. Takemoto Y, Barnes ME, Seward JB, Lester SJ, Appleton CA, Gersh BJ, Bailey KR, Tsang TS (2005) Usefulness of left atrial volume in predicting first congestive heart failure in patients $>$ or $=65$ years of age with well-preserved left ventricular systolic function. Am J Cardiol 96:832-836. doi:10.1016/j.amj card.2005.05.031

5. Rossi A, Cicoira M, Florea VG, Golia G, Florea ND, Khan AA, Murray ST, Nguyen JT, ÓCallaghan P, Anand IS, Coats A, Zardini P, Vassanelli C, Henein M (2006) Chronic heart failure with preserved left ventricular ejection fraction: diagnostic and prognostic value of left atrial size. Int J Cardiol 110:386-392. doi:10.1016/j.ijcard.2005.08.049

6. Simek CL, Feldman MD, Haber HL, Wu CC, Jayaweera AR, Kaul S (1995) Relationship between left ventricular wall thickness and left atrial size: comparison with other measures of diastolic function. J Am Soc Echocardiogr 8:37-47

7. Appleton CP, Galloway JM, Gonzalez MS, Gaballa M, Basnight MA (1993) Estimation of left ventricular filling pressures using two-dimensional and Doppler echocardiography in adult patients with cardiac disease: additional value of analyzing left atrial size, left atrial ejection fraction and the difference in duration of pulmonary venous and mitral flow velocity at atrial contraction. J Am Coll Cardiol 22:1972-1982. doi:10.1016/07351097(93)90787-2
8. Lang RM, Bierig M, Devereux RB, Flachskampf FA, Foster E, Pellikka PA, Picard MH, Roman MJ, Seward J, Shanewise JS, Solomon SD, Spencer KT, Sutton MS, Stewart WJ (2005) Recommendations for chamber quantification: a report from the American Society of Echocardiography's Guidelines and Standards Committee and the Chamber Quantification Writing Group, developed in conjunction with the European Association of Echocardiography, a branch of the European Society of Cardiology. J Am Soc Echocardiogr 18:1440-1463

9. Gutman J, Wang YS, Wahr D, Schiller NB (1983) Normal left atrial function determined by 2-dimensional echocardiography. Am J Cardiol 51:336-340

10. Wang Y, Gutman JM, Heilbron D, Wahr D, Schiller NB (1984) Atrial volume in a normal adult population by two-dimensional echocardiography. Chest 86:595-601

11. Tsang TS, Barnes ME, Gersh BJ, Bailey KR, Seward JB (2002) Left atrial volume as a morphophysiologic expression of left ventricular diastolic dysfunction and relation to cardiovascular risk burden. Am J Cardiol 90:1284-1289

12. Thomas L, Levett K, Boyd A, Leung DY, Schiller NB, Ross DL (2002) Compensatory changes in atrial volumes with normal aging: is atrial enlargement inevitable? J Am Coll Cardiol 40:1630-1635

13. Nagueh SF, Appleton CP, Gillebert TC, Marino PN, Oh JK, Smiseth OA, Waggoner AD, Flachskampf FA, Pellikka PA, Evangelisa A (2009) Recommendations for the evaluation of left ventricular diastolic function by echocardiography. Eur J Echocardiogr 10:165-193. doi:10.1093/ejechocard/jep007

14. Altman DG (1993) Construction of age-related reference centiles using absolute residuals. Stat Med 12:917-924

15. Royston P, Wright EM (1998) How to construct 'normal ranges' for fetal variables. Ultrasound Obstet Gynecol 11:30-38. doi:10. 1046/j.1469-0705.1998.11010030.x

16. Benjamin EJ, D'Agostino RB, Belanger AJ, Wolf PA, Levy D (1995) Left atrial size and the risk of stroke and death. The Framingham Heart Study. Circulation 92:835-841

17. Hudsmith LE, Petersen SE, Francis JM, Robson MD, Neubauer S (2005) Normal human left and right ventricular and left atrial dimensions using steady state free precession magnetic resonance imaging. J Cardiovasc Magn Reson 7:775-782

18. Badano LP, Pezzutto N, Marinigh R, Cinello M, Nucifora G, Pavoni D, Gianfagna P, Fioretti PM (2008) How many patients would be misclassified using $\mathrm{M}$-mode and two-dimensional estimates of left atrial size instead of left atrial volume? A threedimensional echocardiographic study. J Cardiovasc Med (Hagerstown) 9:476-484. doi:10.2459/JCM.0b013e3282f194f0

19. Aune E, Baekkevar M, Roislien J, Rodevand O, Otterstad JE (2009) Normal reference ranges for left and right atrial volume indexes and ejection fractions obtained with real-time threedimensional echocardiography. Eur J Echocardiogr 10:738-744. doi:10.1093/ejechocard/jep054

20. Koka AR, Yau J, Van Why C, Cohen IS, Halpern EJ (2010) Underestimation of left atrial size measured with transthoracic echocardiography compared with 3D MDCT. AJR Am J Roentgenol 194:W375-W381. doi:10.2214/AJR.09.3183

21. Russo C, Hahn RT, Jin Z, Homma S, Sacco RL, Di Tullio MR (2010) Comparison of echocardiographic single-plane versus biplane method in the assessment of left atrial volume and validation by real time three-dimensional echocardiography. J Am Soc Echocardiogr 23:954-960. doi:10.1016/j.echo.2010.06.010

22. Kou S, Caballero L, Dulgheru R, Voilliot D, De Sousa C, Kacharava G, Athanassopoulos GD, Barone D, Baroni M, Cardim N, Gomez De Diego JJ, Hagendorff A, Henri C, Hristova K, Lopez T, Magne J, De La Morena G, Popescu BA, Penicka M, Ozyigit T, Rodrigo Carbonero JD, Salustri A, Van De Veire N, Von Bardeleben RS, Vinereanu D, Voigt JU, Zamorano JL, 
Donal E, Lang RM, Badano LP, Lancellotti P (2014) Echocardiographic reference ranges for normal cardiac chamber size: results from the NORRE study. Eur Heart J Cardiovasc Imaging 15:680-690. doi:10.1093/ehjci/jet284

23. Tsang TSM, Abhayaratna WP, Barnes ME, Miyasaka Y, Gersh BJ, Bailey KR, Cha SS, Seward JB (2006) Prediction of cardiovascular outcomes with left atrial size: is volume superior to area or diameter? J Am Coll Cardiol 47:1018-1023. doi:10.1016/j. jacc.2005.08.077

24. Losi M-A, Betocchi S, Aversa M, Lombardi R, Miranda M, D'Alessandro G, Cacace A, Tocchetti C-G, Barbati G, Chiariello M (2004) Determinants of atrial fibrillation development in patients with hypertrophic cardiomyopathy. Am J Cardiol 94:895-900. doi:10.1016/j.amjcard.2004.06.024

25. Stamler J, Wentworth D, Neaton JD (1986) Is relationship between serum cholesterol and risk of premature death from coronary heart disease continuous and graded? Findings in 356,222 primary screenees of the Multiple Risk Factor Intervention Trial (MRFIT). JAMA 256:2823-2828. doi:10.1001/ jama.1986.03380200061022

26. Kshirsagar AV, Carpenter M, Bang H, Wyatt SB, Colindres RE (2006) Blood pressure usually considered normal is associated with an elevated risk of cardiovascular disease. Am J Med 119:133-141. doi:10.1016/j.amjmed.2005.08.023

27. Giannoni A, Baruah R, Leong T, Rehman MB, Pastormerlo LE, Harrell FE, Coats AJS, Francis DP (2014) Do optimal prognostic thresholds in continuous physiological variables really exist?
Analysis of origin of apparent thresholds, with systematic review for peak oxygen consumption, ejection fraction and BNP. PLoS ONE 9:e81699. doi:10.1371/journal.pone.0081699

28. Nikitin NP, Witte KKA, Thackray SDR, Goodge LJ, Clark AL, Cleland JGF (2003) Effect of age and sex on left atrial morphology and function. Eur J Echocardiogr 4:36-42. doi:10.1053/ euje.4.1.36

29. Russo C, Jin Z, Homma S, Rundek T, Elkind MS, Sacco RL, Di Tullio MR (2012) Left atrial minimum volume and reservoir function as correlates of left ventricular diastolic function: impact of left ventricular systolic function. Heart 98:813-820. doi:10. 1136/heartjnl-2011-301388

30. Spencer KT, Mor-Avi V, Gorcsan J, DeMaria AN, Kimball TR, Monaghan MJ, Perez JE, Weinert L, Bednarz J, Edelman K, Kwan OL, Glascock B, Hancock J, Baumann C, Lang RM (2001) Effects of aging on left atrial reservoir, conduit, and booster pump function: a multi-institution acoustic quantification study. Heart 85:272-277. doi:10.1136/heart.85.3.272

31. Dalen H, Thorstensen A, Vatten LJ, Aase SA, Stoylen A (2010) Reference values and distribution of conventional echocardiographic Doppler measures and longitudinal tissue Doppler velocities in a population free from cardiovascular disease. Circ Cardiovasc Imaging 3:614-622. doi:10.1161/CIRCIMAGING. 109.926022

32. Lester SJ, Ryan EW, Schiller NB, Foster E (1999) Best method in clinical practice and in research studies to determine left atrial size. Am J Cardiol 84:829-832. doi:10.1016/S0002-9149(99)00446-4 